Letter to the Editor

\title{
Volumetric and functional left atrial abnormalities in different disorders - are these alterations specific?
}

\section{A R T I C L E I N F O}

\section{Keywords}

Left atrial

Three-dimensional

Speckle-tracking echocardiography

I am reading the paper of Keulards et al. in which the relationship between coronary microvascular resistance and left atrial (LA) strains as assessed by two-dimensional speckle-tracking echocardiography (2DSTE) was investigated [1]. Although the manuscript is well written and the discussion is clear, it needs some revision. Three-dimensional (3D) speckle-tracking echocardiography (3DSTE) is a more advanced non-invasive imaging method than 2DSTE. During 3DSTE, the same virtually created 3D model of the LA can be used for simultaneous assessment not only of LA strains but LA volumes and volume-based functional properties including stroke volumes and emptying fractions respecting the cardiac cycle as well allowing detailed assessment of the LA (2). In some disorders, only mild volumetric changes could be demonstrated without global LA strain abnormalities affecting only certain phases of LA function like in young patients with type 1 diabetes mellitus [2]. In noncompaction and hypertrophic cardiomyopathies and cardiac amyloidosis, significant LA volumetric and contractility abnormalities represented by LA strains could be demonstrated affecting all phases of LA function [2,3]. Interestingly, moderate LA abnormalities were found in elite athletes, as well [4]. While 'abnormalities' meant deterioration of LA contractility represented by reduced LA strains in these disorders, significant augmentation of LA contractility represented by increase in certain LA strains was present in acromegaly, suggesting their compensatory effects [5]. All these abnormalities could be explained by disease-associated volume and/or pressure changes, coronary perfusion abnormalities (resistance), alterations in tissue quality including storage, fibrosis, edema, etc. However, important questions remained unanswered such as: are these changes associated with these non-valvular disorders are specific? What happens with aging and treatment? Therefore, further studies are warranted to confirm these findings and to clarify any prognostic impact as well.

\section{References}

[1] D.C.J. Keulards, S. Bouwmeester, A.M.J. de Vos, L.R.C. Dekker, N.H.J. Pijls, P. Houthuizen, High microvascular resistance and reduced left atrial strain in patients with coronary microvascular dysfunction: the micro-strain study, Int. J. Cardiol. 333 (2021) 21-28, https://doi.org/10.1016/j.ijcard.2021.02.055.

[2] A. Nemes, P. Domsik, A. Kalapos, T. Forster, Is three-dimensional speckle-tracking echocardiography able to identify different patterns of left atrial dysfunction in selected disorders? Short summary of the MAGYAR-Path Study, Int. J. Cardiol. 220 (2016) 535-537.

[3] D. Földeák, Á. Kormányos, P. Domsik, A. Kalapos, G.Á. Piros, N. Ambrus, Z. Ajtay, R. Sepp, Z. Borbényi, T. Forster, A. Nemes, Left atrial dysfunction in light-chain cardiac amyloidosis and hypertrophic cardiomyopathy - a comparative threedimensional speckle-tracking echocardiographic analysis from the MAGYAR-Path Study, Rev. Port. Cardiol. 36 (2017) 905-913.

[4] A. Nemes, P. Domsik, A. Kalapos, A. Orosz, M. Oszlánczi, L. Török, L. Balogh, J. Márton, T. Forster, C. Lengyel, Volumetric and functional assessment of the left atrium in young competitive athletes without left ventricular hypertrophy: the MAGYAR-Sport Study, J. Sports Med. Phys. Fitness. 57 (2017) 900-906.

[5] Á. Kormányos, P. Domsik, A. Kalapos, Z. Valkusz, C. Lengyel, T. Forster, A. Nemes, Three-dimensional speckle tracking echocardiography-derived left atrial deformation analysis in acromegaly (results from the MAGYAR-Path Study), Echocardiography. 35 (2018) 975-984.

Attila Nemes

Department of Medicine, Medical Faculty, Albert Szent-Györgyi Clinical Center, University of Szeged, Szeged, Hungary

" Corresponding author at: Department of Medicine, Medical Faculty, Albert Szent-Györgyi Clinical Center, University of Szeged, H-6725 Szeged, Semmelweis street 8, P.O. Box 427, Hungary. E-mail address: nemes.attila@med.u-szeged.hu. 